\title{
Incidence and Risk Factors for Amputation in Patients With Diabetes in Japan: A Historical Cohort Study Using a Nationwide Claims Database
}

Masanori Kaneko

Niigata University: Niigata Daigaku

Kazuya Fujihara ( $\boldsymbol{\nabla}$ kafujihara-dm@umin.ac.jp )

Niigata University: Niigata Daigaku https://orcid.org/0000-0001-6725-4169

Taeko Osawa

Niigata University: Niigata Daigaku

Masahiko Yamamoto

Niigata daigaku

Mayuko Yamada Harada

Niigata Daigaku

Masaru Kitazaws

Niigata Daigaku

Yasuhiro Matsubayashi

Niigata Daigaku

Takaho Yamada

Niigata Daigaku

Hiroyasu Seida

JMDC Inc.

Satoru Kodama

Niigata Daigaku

Hirohito Sone

Niigata Daigaku

\section{Research}

Keywords: lower limb amputation, risk factor, HbA1c, age, Asian people

Posted Date: December 16th, 2020

DOI: https://doi.org/10.21203/rs.3.rs-125853/v1 
License: (c) (i) This work is licensed under a Creative Commons Attribution 4.0 International License. Read Full License

Version of Record: A version of this preprint was published at Journal of Foot and Ankle Research on April 9th, 2021. See the published version at https://doi.org/10.1186/s13047-021-00474-8. 


\section{Abstract}

Background: Because amputation negatively affects the quality of life of patients with diabetes and increases the risk of cardiovascular events and mortality, predictors of amputation must be identified. However, no large cohort studies have been conducted regarding the incidence of amputation in patients with diabetes in East Asia.

Methods: We analyzed data from a nationwide claims database in Japan accumulated from 2008-2016, involving 17,288 patients with diabetes aged 18-72 y (2942 women, mean age 50.2 y, HbA1c 7.2\%).

Results: The mean follow-up time was 5.3 years, and 16 amputations occurred (0.17/1000 person-years). Multivariate Cox regression analysis showed that age and $\mathrm{HbA} 1 \mathrm{c}$ levels were independent predictors of amputation (hazard ratios [HRs], 1.09 and 1.43; 95\% confidence intervals [Cls], 1.01-1.16 and 1.12-1.82, respectively). Compared with patients aged $<60 \mathrm{y}$ and with $\mathrm{HbA} 1 \mathrm{c}<8 \%$, the $\mathrm{HR}$ for patients aged $\geq 60 \mathrm{y}$ and with $\mathrm{HbA} 1 \mathrm{C} \geq 8 \%$ was 32.1 (95\% $\mathrm{Cl}, 7.30-141.2)$.

Conclusions: Improved glycemic control may lower amputation risk.

\section{Background}

The number of patients with diabetes mellitus is increasing worldwide, and diabetic complications represent serious health and economic problems. Lower limb amputation is a serious complication of diabetes and markedly reduces patients' quality of life. Diabetic patients who have undergone a lower limb amputation have higher risks of cardiovascular events and death [1]. Although the risk of amputation differs among ethnic groups [2], the incidence of lower limb amputation is low in East Asia. However, the diabetic patient population is relatively young in some urban areas, but lower limb amputations still appear to be relatively frequent in these areas. Few previous studies have evaluated the risk of lower limb amputation in Japan. Therefore, we aimed to determine the incidence of lower limb amputations in Japanese patients with diabetes and classified this according to age and HbA1c level. To this end, we analyzed a nationwide claims database that contains data for individuals with a mean age of 50 years. The results of this analysis should provide a reliable guide regarding the risk of lower limb amputation in this age group.

\section{Methods}

We analyzed data from a nationwide claims database that included 296,504 people enrolled with a health insurance provider for company employees and their dependents in Japan. We analyzed 17,288 people with diabetes mellitus (mean age, $50.2 \mathrm{y} ; \mathrm{HbA} 1 \mathrm{c}, 7.2 \%$ ). Details of the study were described previously $[3,4]$. Individuals aged $18-72$ years with diabetes who had been followed for at least 3 years between 1 April 2008 and 31 March 2013 and followed through 31 August 2016 were eligible for the study. Diabetes was determined by an FPG $\geq 7.0 \mathrm{mmol} / \mathrm{L}$ or $\mathrm{HbA} 1 \mathrm{c} \geq 6.5 \%$ or both without prescription of an antidiabetic drug or with a prescription of an antidiabetic drug regardless of FPG or HbA1c. 
Amputation occurrence was determined according to claims using the International Classification of Diseases 10th revision (ICD-10) codes and medical procedure data after 1 month of follow-up. A Cox regression model identified variables related to the overall amputation incidence. Analyses were performed using SPSS (version 19.0, Chicago, IL, USA). Statistical significance was considered at $\mathrm{P}<$ 0.05. The Ethics Committee of the Niigata University approved this study.

This research was done without patient involvement. Patients were not invited to comment on the study design and were not consulted to develop patient-relevant outcomes or interpret the results. Patients were not invited to contribute to the writing or editing of this document for readability or accuracy.

\section{Results}

Table 1 presents the baseline characteristics of patients who did and did not undergo lower limb amputation. Diabetes duration, patient age, and systolic blood pressure were all significantly higher in the amputation group than in the no-amputation group.

During a mean 5.3-year follow-up, 16 amputations occurred (0.17/1000 person-years). Multivariate Cox regression analysis showed that age and $\mathrm{HbA} 1 \mathrm{c}$ were independent predictors of amputation (hazard ratios [HRs] 1.09 and 1.43; 95\% confidence intervals [Cls] 1.01-1.16 and 1.12-1.82, respectively; Supplemental Table 2). Comparing the hazard ratio by dividing it by 60 years of age with an $8 \% \mathrm{HbA} 1 \mathrm{c}$ showed that the HR was $3.2(95 \% \mathrm{Cl} 0.91-11.3)$ for those aged $\geq 60$ years and with an $\mathrm{HbA} 1 \mathrm{c}<8 \%$ and $4.9(95 \% \mathrm{Cl} 1.1-21.5)$ for those aged $<60$ years and with an $\mathrm{HbA} 1 \mathrm{c} \geq 8 \%$. Compared with patients aged $<$ 60 years and with an $\mathrm{HbA} 1 \mathrm{c}<8 \%$, the $\mathrm{HR}$ for those aged $\geq 60$ and an $\mathrm{HbA} 1 \mathrm{c} \geq 8 \%$ was $32.1(95 \% \mathrm{Cl}$ 7.30-141.2; Fig. 1). Older participants and those with higher HbA1c levels presented an increased risk of lower limb amputation.

\section{Discussion}

The amputation rate is much lower in Japanese patients with diabetes than in Western populations [2]. Higher $\mathrm{HbA} 1 \mathrm{c}$ values represent a major risk factor for amputation, leading to the speculation that effective glycemic control is associated with a lower amputation risk by preventing progression of diabetic neuropathy and/or exacerbation of infection. A study on the frequency of lower limb amputations in a Japanese hospital specializing in diabetes mellitus (average patient age, 65 years) showed a lower limb amputation frequency of 0.47 per 1,000 persons/year [5]. Participants in our analysis were slightly younger (average age, 54 years), and our participants included fewer elderly people; therefore, the lower limb amputation frequency may have been lower.

The prevalence of lower limb amputations has been reported to be higher in diabetic patients than in those without diabetes. A Swedish study showed that the atraumatic lower limb amputation rate was approximately eight times higher in patients with diabetes than in those without diabetes [6]. Additionally, hyperglycemia and $\mathrm{HbA} 1 \mathrm{c}$ elevation were shown to be risk factors for lower limb amputation in diabetic 
patients [7]. A high degree of hyperglycemia is thought to delay wound healing and significantly increase the risk of wound infection after surgery [8]. A 7-year follow-up study of diabetic patients showed that elevated $\mathrm{HbA} 1 \mathrm{c}$ was positively correlated with the risk of lower limb amputation and that the frequency of lower limb amputations increased linearly as the glycemic control worsened [9].

In a national nutrition survey conducted from 1999-2000 in the United States, the frequency of lower limb amputations increased with age among diabetic patients [10]. A survey by the Ministry of Health, Labour and Welfare showed that the average life expectancy in Japan in 2015 was 80 years in men and 87 years in women, which is the highest life expectancy ever reported worldwide. With the extended average life expectancy, the proportion of people aged $\geq 65$ years in Japan's total population (127.08 million as of October 1,2014 ) reached $26.0 \%$ (33 million) and is expected to reach $40.0 \%$ in 2060. As the population ages, the number of elderly people with diabetes also increases. Data from 2001-2010 showed that the average life expectancy of diabetic patients was 71.4 years for men and 75.1 years for women. This was extended by 3.4 years for men and 3.5 years for women compared with the average life span surveyed from 1991-2000 [11]. As the aging population increases in Japan, China and other Asian countries, the frequency of lower limb amputations may increase in East Asia.

The proportion of lower limb amputations in diabetic patients has decreased by approximately half in the last 20 years [10], possibly owing to better glycemic and lipid control. Although the absolute number of lower limb amputations among diabetic patients has decreased, in our study, the risk of lower limb amputation increased as the HbA1c levels increased. In the UK Prospective Diabetes Study, death due to lower limb amputation and arteriosclerosis obliterans increased as the HbA1c increased. Conversely, each $1 \%$ decrease in $\mathrm{HbA} 1 \mathrm{c}$ reduces the $\mathrm{HR}$ for amputation or death from peripheral vascular disease by $43 \%$. Thus, effective blood glucose control may help reduce the frequency of lower limb amputations [12]. Elderly patients can often tolerate high blood glucose and HbA1c levels; however, their risk of lower limb amputation increases. Therefore, clinicians should carefully observe the conditions of their lower limbs during examinations and provide individualized interventions.

Our analysis did not show smoking as a significant risk factor for lower limb amputation. However, smoking remains a risk factor for cardiovascular events and various cancers [13], and smoking cessation remains important in treating diabetes.

One limitation of this study was that no examinations were performed to check for the presence or absence of lower limb ulcers. The risk of lower limb amputation is considered high in patients with a high frequency of lower limb ulcers.

\section{Conclusions}

The lower limb amputation frequency is lower in Japanese populations than in Europe and the United States [2]. Compared with patients aged $<60$ years and with an $\mathrm{HbA1c}<8 \%$, the risk for amputation was 32 times higher among those aged $\geq 60$ years and with an $\mathrm{HbA1c} \geq 8 \%$. 


\section{List Of Abbreviations}

FPG; Fasting plasma glucose HRs; Hazard ratios

\section{Declarations}

\section{Ethics approval and consent to participate}

The Ethics Committee of the Niigata University approved this study(2015-2410).

\section{Consent for publication}

Not applicable.

\section{Availability of data and materials}

The data and study materials will not be made available to other researchers for purposes of reproducing the results or replicating the procedure.

\section{Competing interests}

JMDC, Inc. created a nationwide claims-based database for our group, without receiving payment. Although members of this organization participated in preparing this manuscript, they did not contribute to the data analysis or the conclusions made. Thus, we feel that this does not represent a potential conflict of interest.

\section{Funding}

This work was supported in part by the Japan Society for the Promotion of Science (18K17897).

\section{Authors' contributions}

$\mathrm{MK}, \mathrm{KF}$ and HS conceived and designed the study and supervised the research. KF, NY and HS acquired the data. MK, TO, MY, MH, MK, YM and TY analyzed and interpreted the data. MK and KF prepared the figures and wrote and revised the manuscript. All authors contributed to drafting the article or revising it critically for important intellectual content and approved the final version to be submitted.

\section{Acknowledgements}

This work was supported in part by JMDC, Inc. We appreciate their provision of the database used in this research. The authors also thank Mami Haga and Natsuko Tada, Niigata University Faculty of Medicine, for their excellent secretarial assistance. We also thank Traci Raley, MS, ELS, from Edanz Group (https://en-author-services.edanzgroup.com/ac) for editing a draft of this manuscript.

\section{References}


1. Apelqvist J, Larsson J, Agardh CD. Long-term prognosis for diabetic patients with foot ulcers. J Intern Med. 1993;233:485-91.

2. Robinson TE, Kenealy T, Garrett M, Bramley D, Drury PL, Elley CR. Ethnicity and risk of lower limb amputation in people with Type 2 diabetes: a prospective cohort study. Diabet Med. 2016;33:55-61.

3. Fujihara $K$, Igarashi R, Yamamoto $M$, Ishizawa M, Matsubayasi $Y$, Matsunaga $S$, et al. Impact of glucose tolerance status on the development of coronary artery disease among working-age men. Diabetes Metab. 2017;43:261-4.

4. Kimura S, Sato T, Ikeda S, Noda M, Nakayama T. Development of a database of health insurance claims: standardization of disease classifications and anonymous record linkage. J Epidemiol. 2010;20:413-9.

5. Iwase M, Fujii H, Nakamura U, Ohkuma T, Ide H, Jodai-Kitamura T. Incidence of diabetic foot ulcer in Japanese patients with type 2 diabetes mellitus: The Fukuoka diabetes registry. Diabetes Res Clin Pract. 2018;137:183-9.

6. Johannesson A, Larsson GU, Ramstrand N, Turkiewicz A, Wirehn AB, Atroshi I. Incidence of lowerlimb amputation in the diabetic and nondiabetic general population: a 10-year population-based cohort study of initial unilateral and contralateral amputations and reamputations. Diabetes Care. 2009;32:275-80.

7. Adler Al, Erqou S, Lima TA, Robinson AH. Association between glycated haemoglobin and the risk of lower extremity amputation in patients with diabetes mellitus-review and meta-analysis. Diabetologia. 2010;53:840-9.

8. Wukich DK, McMillen RL, Lowery NJ, Frykberg RG. Surgical site infections after foot and ankle surgery: a comparison of patients with and without diabetes. Diabetes Care. 2011;34:2211-3.

9. Lehto S, Ronnemaa T, Pyorala K, Laakso M. Risk factors predicting lower extremity amputations in patients with NIDDM. Diabetes Care. 1996;19:607-12.

10. Gregg EW, Sorlie P, Paulose-Ram R, Gu Q, Eberhardt MS, Wolz M, et al. Prevalence of lower-extremity disease in the US adult population $>=40$ years of age with and without diabetes: 1999-2000 national health and nutrition examination survey. Diabetes Care. 2004;27:1591-7.

11. Nakamura J, Kamiya H, Haneda M, Inagaki N, Tanizawa Y, Araki E, et al. Causes of death in Japanese patients with diabetes based on the results of a survey of 45,708 cases during 20012010: Report of the Committee on Causes of Death in Diabetes Mellitus. J Diabetes Investig. 2017;8:397-410.

12. Stratton IM, Adler Al, Neil HA, Matthews DR, Manley SE, Cull CA, et al. Association of glycaemia with macrovascular and microvascular complications of type 2 diabetes (UKPDS 35): prospective observational study. BMJ. 2000;321:405-12.

13. Tan CE, Glantz SA. Association between smoke-free legislation and hospitalizations for cardiac, cerebrovascular, and respiratory diseases: a meta-analysis. Circulation. 2012;126:2177-83.

\section{Table}


Table 1 not available with this version.

\section{Figures}

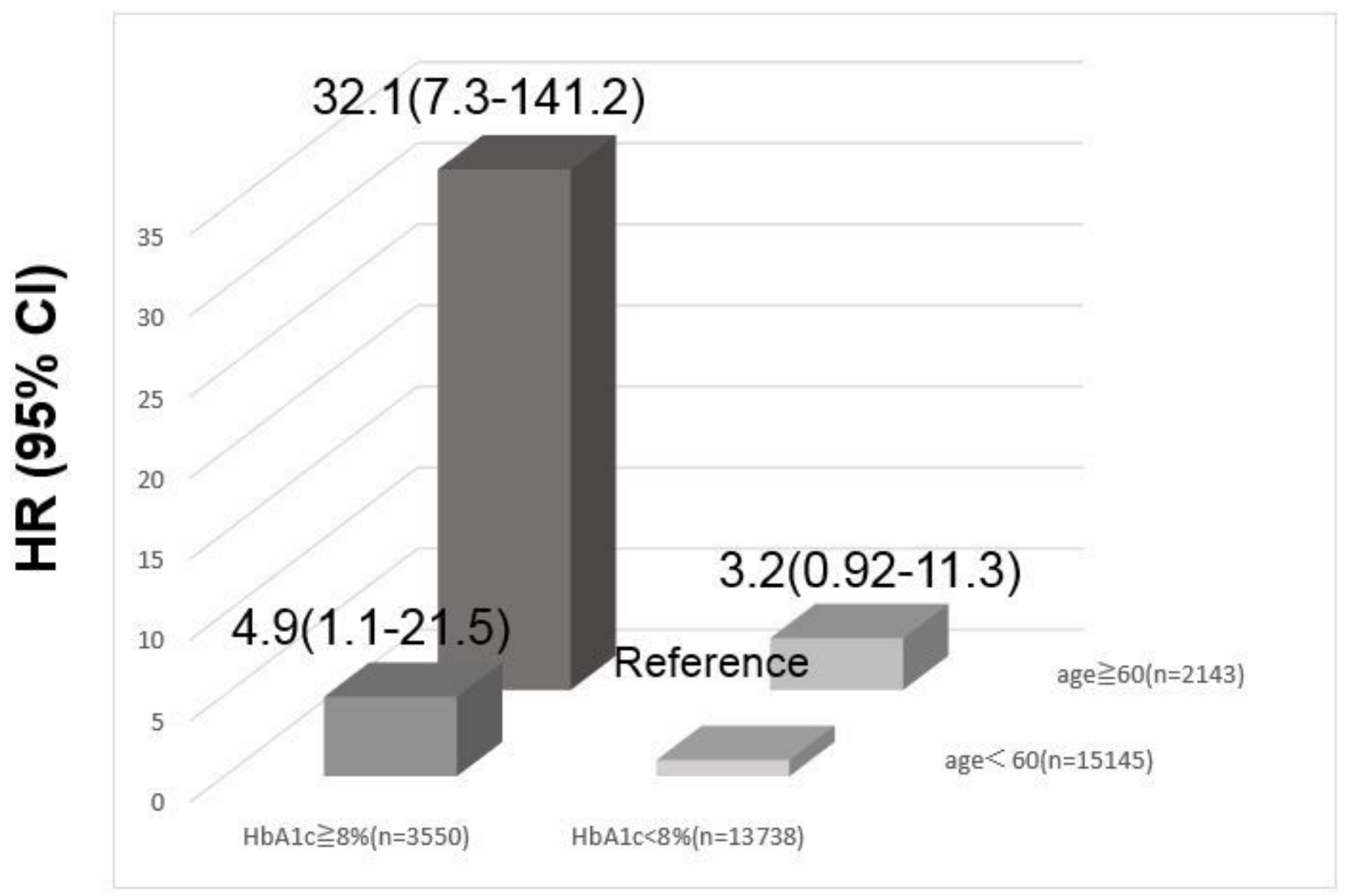

\section{Figure 1}

$\mathrm{HR}$ for lower limb amputation according to combinations of $\mathrm{HbA} 1 \mathrm{c}$ and age The HR for those aged $\geq 60$ years with an $\mathrm{HbA} 1 \mathrm{c}<8 \%$ was $3.2(95 \% \mathrm{Cl} 0.91-11.3)$; the $\mathrm{HR}$ for those aged $<60$ years with an $\mathrm{HbA} 1 \mathrm{c}$ $\geq 8 \%$ was 4.9 (95\% $\mathrm{Cl} 1.1-21.5)$. The $\mathrm{HR}$ for those aged $\geq 60$ years with an $\mathrm{HbA} 1 \mathrm{c} \geq 8 \%$ was 32.1 (95\% $\mathrm{Cl}$ 7.30-141.2), compared with those aged $<60$ years with an $\mathrm{HbA} 1 \mathrm{c}<8 \%$ (the reference group). 


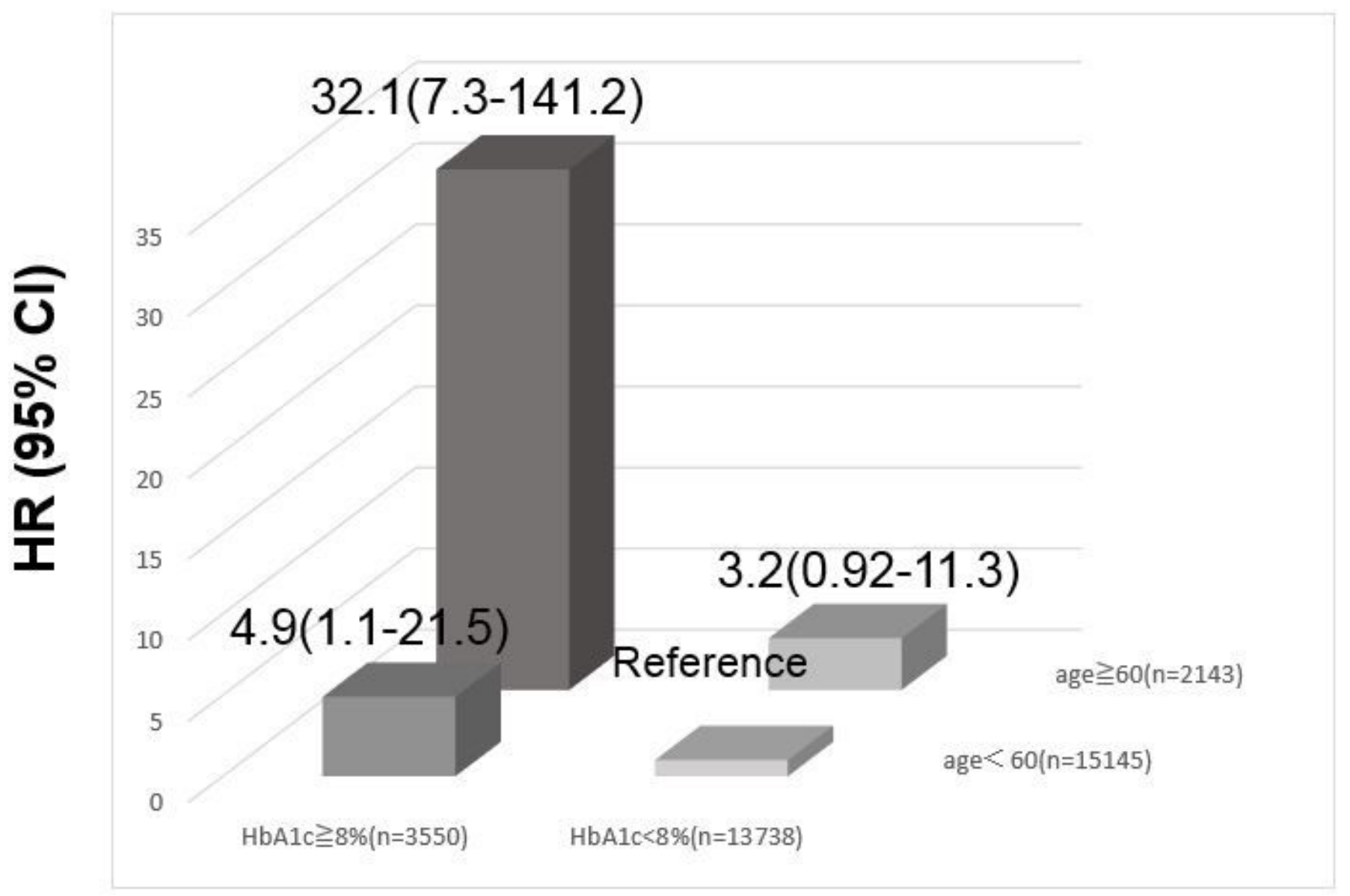

Figure 1

$\mathrm{HR}$ for lower limb amputation according to combinations of $\mathrm{HbA} 1 \mathrm{c}$ and age The HR for those aged $\geq 60$ years with an $\mathrm{HbA} 1 \mathrm{c}<8 \%$ was $3.2(95 \% \mathrm{Cl} 0.91-11.3)$; the $\mathrm{HR}$ for those aged $<60$ years with an $\mathrm{HbA} 1 \mathrm{c}$ $\geq 8 \%$ was 4.9 ( $95 \% \mathrm{Cl} 1.1-21.5)$. The $\mathrm{HR}$ for those aged $\geq 60$ years with an $\mathrm{HbA} 1 \mathrm{C} \geq 8 \%$ was $32.1(95 \% \mathrm{Cl}$ 7.30-141.2), compared with those aged $<60$ years with an $\mathrm{HbA} 1 \mathrm{c}<8 \%$ (the reference group).

\section{Supplementary Files}

This is a list of supplementary files associated with this preprint. Click to download.

- Supplementaltable20201204.docx

- Supplementaltable20201204.docx 